\title{
A Study of the Mechanisms of Internal Short Circuit in a Li/Li Cell by Synchrotron X-ray Phase Contrast Tomography"
}

Fu Sun, ${ }^{* ; \dagger ; \S}$ Riko Moroni, Kang Dong, ${ }^{\dagger ; \S}$ Henning Markötter, ${ }^{\S}$ Dong Zhou, ${ }^{\dagger ; \S}$ André Hilger, ${ }^{\S}$ Lukas Zielke, ${ }^{\ddagger}$ Roland Zengerle, ${ }^{\ddagger}$ Simon Thiele, ${ }^{\ddagger, \#}$ John Banhart, ${ }^{\dagger, \S}$ and Ingo Manke ${ }^{\S}$

${ }^{\dagger}$ Institute of Material Science and Technologies

Technical University Berlin

Strasse des 17. Juni 135, 10623 Berlin, Germany

${ }^{\ddagger}$ Laboratory for MEMS Applications, IMTEK Department of Microsystems Engineering

University of Freiburg

Georges-Koehler-Allee 103, 79110 Freiburg, Germany

${ }^{\S}$ Helmholtz Centre Berlin for Materials and Energy

Hahn-Meitner-Platz 1,

14109 Berlin, Germany

\#FIT, University of Freiburg

Georges-Köhler-Allee 105, 79110 Freiburg, Germany

\# published in: ACS Energy Letters 2(1), 94-104 (2017

American Chemical Society, ESSN: 2380-8195 — doi: 10.1021/acsenergylett.6b00589

Knowledge about degradation and failure of Li-ion batteries (LIBs) is of paramount importance especially because failure can be accompanied by severe hazards. To contribute to the understanding of such phenomena synchrotron in-line phase contrast Xray tomography was employed to investigate internal cell deformation and degradation caused by an internal short circuit (ISC). The tomographic images taken from an uncycled $\mathrm{Li} / \mathrm{Li}$ cell and a short-circuited $\mathrm{Li} / \mathrm{Li}$ cell reveal how lithium microstructures (LmS) develop during electrochemical stripping and plating during discharge and charge and how the three-layer separator used is damaged by growing LmSs and delaminates and melts as a consequence of an ISC. Previously unknown insights into the internal cell degradation and deformation mechanisms caused by an ISC are obtained and provide hints of how the properties of the separator could be modified in order to improve the reliability and safety of current and next-generation LIBs. 
Safety and reliability of lithium ion batteries (LIBs) that are targeted for high-power and highenergy applications are a major concern. ${ }^{1-14}$ For example, the most promising Li metal-based battery technologies such as lithium-sulphur and lithium-air batteries have not been successfully commercialized mainly because of the uncontrolled growth of lithium microstructures (LmSs) such as dendrites, fibers, whiskers, moss, etc., which can cause internal short circuit (ISC) of a cell and result in catastrophic fires or even explosions. ${ }^{15-17}$ Recent field incidents such as fires on a Boeing 787 Dreamliner flight and in a Tesla electric vehicle (EV) or even in the Samsung Note 7 smartphone are believed to be closely linked to ISCs in LIBs. ${ }^{18-20}$ Furthermore, the soaring number of EVs in use additionally adds tremendous weight to safety and reliability in presentand next-generation LIB technology. In order to gain a detailed understanding of internal cell deformation and degradation leading to ISCs, various testing techniques such as using a blunt rod to indent a cell as developed by the Underwrites Laboratory and the U.S. Advanced Battery Consortium, surface indentation or pinch test as developed by Motorola, and the forced ISC approach developed by the Battery Association of Japan have been employed. ${ }^{21}$ The purpose of these tests is to create a small break in the separator by exerting an external force, mimicking ISC events that may lead to failed incidents in LIBs. Unfortunately, recent investigations have demonstrated that such mechanical intrusion methods are not entirely representative of true spontaneous ISCs due to the destructive and post-mortem nature of characterization, which eliminates much of the in situ deformation information. ${ }^{22-23}$ Although a non-mechanical approach to initiate an ISC has been reported by Christopher et al. by using different melting point metals and metal alloys, ${ }^{21}$ the challenge of a detailed characterization of an ISC by sophisticated characterization tool in a non-destructive way remains.

To this end, various investigations employing light microscopy, ${ }^{24}$ nuclear magnetic resonance ${ }^{25}$ (NMR) and ${ }^{7} \mathrm{Li}$ magnetic resonance imaging ${ }^{26}$ (MRI), scanning electron microscopy ${ }^{27-28}$ (SEM) and transmission electron microscopy ${ }^{29-30}$ (TEM) have been carried out to characterize the complicated LmS growth, which is thought to lead to the ultimate ISC event. However, these reports mainly focus on the growth of LmSs and ignore the accompanying morphological evolution of the separators as well as the correlation between growing LmS and cell failure. Hitherto, no experiments have been reported in the battery community that aim at investigating the mechanisms of ISCs leading to (internal) cell degradation. Whilst different strategies have been proposed to avoid ISC-induced battery failures, ${ }^{31-38}$ it remains of fundamental interest to directly visualize the ISC caused by growing LmSs in order to fundamentally understand the failure mechanism of LIBs and thereafter be able to improve their properties for current and future usage.

Recently, synchrotron X-ray imaging has evolved into a powerful characterization tool in materials science ${ }^{39}$ and has enabled battery researchers to obtain unprecedented insights into the underlying degradation mechanisms of LIBs non-destructively. ${ }^{40-41}$ Among these, Eastwood et al. have characterized the 3D microstructure of electrodeposited LmSs by synchrotron in-line phase contrast X-ray tomography, demonstrating that this technique is a suitable tool for investigating 
LmSs without removing the sample from its as-grown environment. ${ }^{42}$ Moreover, Harry et al. have characterized both the LmS and the separator punctured by the LmS simultaneously, further demonstrating that this technique is also suitable for studying the interaction between LmS and separator simultaneously. ${ }^{43}$ Nevertheless, Harry et al. have employed a custom-made polystyrene-block-poly (ethylene oxide) copolymer electrolyte as a separator and they conducted their characterization ex situ. From a practical point of view though, non-destructive investigations using widely adopted commercial separators would allow for more general conclusions on how and why separators fail and ISC develops. Obviously, fundamental research on actual kinematic processes of ISC associated with commercial separators is highly desired.

Currently, the most widely used commercial separators in LIBs are made of polyolefin materials such as polyethylene (PE) and polypropylene (PP) due to their proper pore structure, good mechanical strength and acceptable costs. ${ }^{32,}{ }^{34}$ In this work, the commercially available trilayer Celgard $^{\circledR} 2325$ separator $^{44-45}$ is studied. The mechanism of its failure that leads to an internal ISC caused by the growing LmS is investigated via in-line phase contrast X-ray tomography. The separator investigated here is made of a PE layer of a low melting point (m.p. $135^{\circ} \mathrm{C}$ ), sandwiched between two PP layers of higher melting point (m.p. $165^{\circ} \mathrm{C}$ ). In the case of overheating, the middle PE layer will shut down the cell automatically by blocking ionic pathways upon melting, while the two PP layers can still provide mechanical strength to prevent physical contact of the electrodes. This proposed shutdown function is meant to dispel safety concerns related to ISCs in LIBs.

Here, we present a non-destructive characterization of an ISC in a $\mathrm{Li} / \mathrm{Li}$ symmetrical cell for the first time. We demonstrate that: 1) most of the electrochemically deposited LmSs are electrochemically inert during ensuing Li stripping, 2) electrochemical stripping and plating during discharge and charge are highly non-uniformly distributed, 3) delamination into three native layers and partial melting of the trilayer Celgard $^{\circledR} 2325$ separator can develop in a real ISC event, 4) decomposition of the solid electrolyte interface (SEI) covering the LmSs and partial melting and re-solidifying of porous LmSs can also occur due to localized excessive Joule heating resulting from the ISC. These unexpected findings, which are not accessible by conventional electrochemical and morphological characterizations, shed new light on the kinematic process of ISC and could open up new design principles and opportunities to fundamentally improve the safety and reliability of current- and next-generation LIBs.

Cell preparation, imaging setup and data acquisition A proof-of-concept cell that is compatible with synchrotron X-ray tomography is designed and fabricated as shown in Figure 1 along with a schematic illustration of the synchrotron imaging setup at the BAMline, BESSY II in Berlin, Germany. ${ }^{46-48}$ An electrochemical validation of the presently designed cell can be found in our previous reports. ${ }^{49-50}$ SEM images of the surface and a cross-section of the employed trilayer Celgard $^{\circledR} 2325$ separator are shown in Figure 2. From Figure 2a, the distinct slit-pore structure that results from extrusion and unidirectional stretching during the dry-process manufacture method is clearly observed. ${ }^{44}$ The three-layer structure of the PP/PE/PP sandwich with a total 
thickness of $\sim 25 \mu \mathrm{m}$ is shown in Figure 2b. ${ }^{44-45}$ Symmetrical cells made of Li metal electrodes, the trilayered separator and the standard electrolyte $\left(1 \mathrm{M} \mathrm{LiPF}_{6}\right.$ in ethylene carbonate (EC) and ethyl methyl carbonate (EMC) (EC/EMC=50/50 (vol/vol)) were assembled. Two Li symmetrical cells were investigated here, one being in the pristine state (without any cycling, hereafter named $\mathrm{Li} / \mathrm{Li}-1$ ) and the other one being short-circuited after $13.4 \mathrm{~h}$ charge (evidenced by a sudden voltage drop shown in Figure 2d, hereafter named Li/Li-2). Both cells were mounted on the setup for characterization without prior disassembly. Every tomography was recorded by a detector system with $0.438 \mu \mathrm{m}$ pixel size. 2200 projections covering $180^{\circ}$ rotation angle were acquired. The field of view (FoV) was $(1.7 \times 1.2) \mathrm{mm}^{2}$ (length $\times$ height). Detailed cycling parameters and the procedure of normalization, tomography reconstruction and $3 \mathrm{D}$ presentation are given in the Experimental Methods section. ${ }^{51-52}$

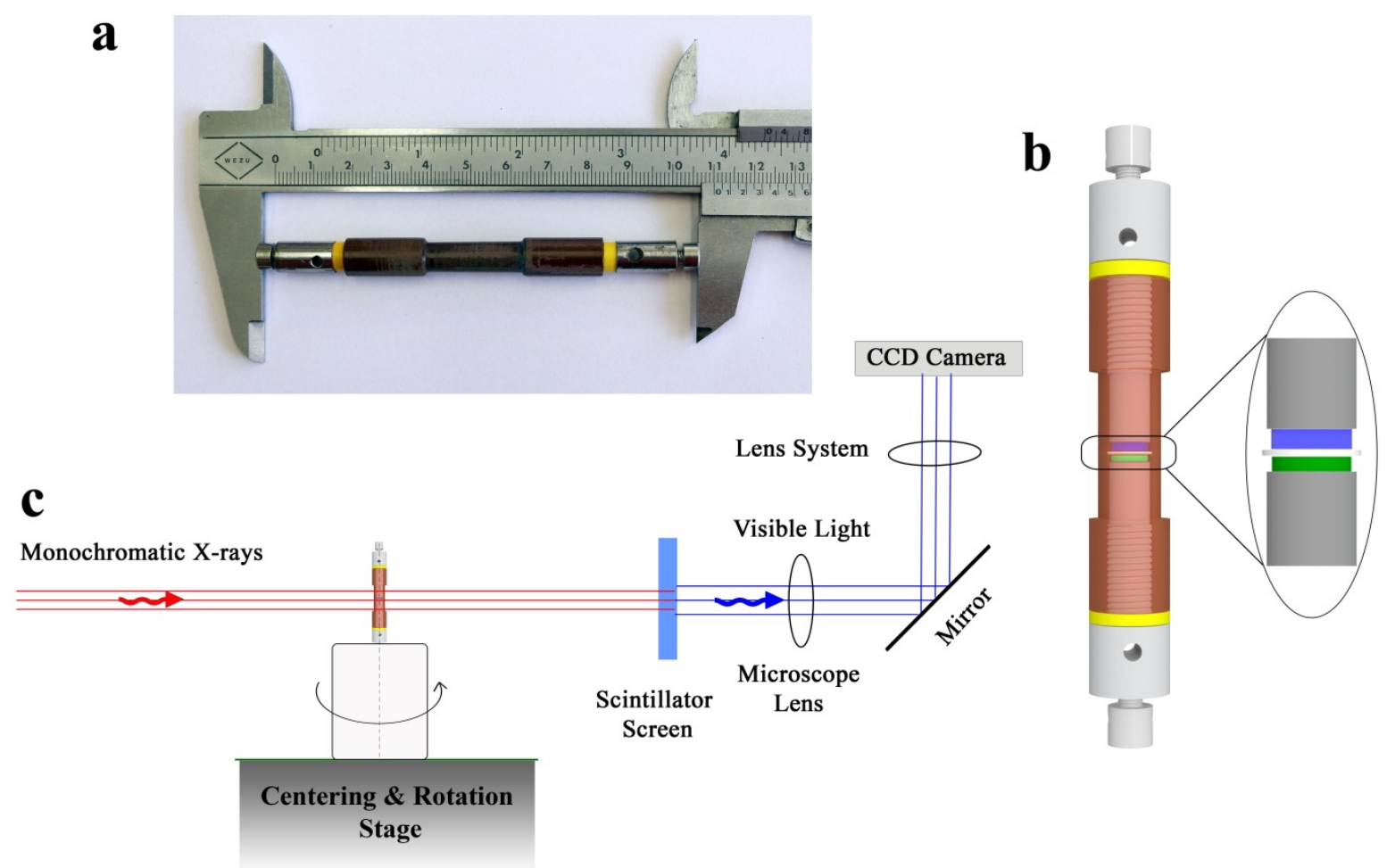

Figure 1. a) Photograph of the fabricated proof-of-concept cell. b) Corresponding schematic representation of the cell consisting of a polyamide-imide housing (brown), two screw electrodes and retaining screws each on top (light grey), two sealing rings (yellow), a porous separator (white) sandwiched between two electrodes (blue and green). c) Schematic representation of the experimental setup of the tomography station at the BAMline at BESSY II, Helmholtz-Zentrum Berlin, Germany. Figure 1 has been adapted from Ref $^{50}$, with permission by the American Chemical Society.

Morphological characterization of $\mathrm{Li} / \mathrm{Li}-1$ cell and electrochemical characterization of $\mathrm{Li} / \mathrm{Li}-2$ cell A cross-sectional X-ray tomographic slice of the uncycled $\mathrm{Li} / \mathrm{Li}-1$ cell is shown in Figure 2c, 
in which the two Li electrodes and the separator are clearly discernable due to the partially light and partially dark boundaries between them arising from in-line phase contrast. ${ }^{42,53}$ The interface between the $\mathrm{Li}$ electrode and the separator of $\mathrm{Li} / \mathrm{Li}-1$ cell is flat and gapless. The $\mathrm{Li} / \mathrm{Li}-2$ cell was galvanostatically "cycled" until an internal short circuit occurred. The voltage curve of the $\mathrm{Li} / \mathrm{Li}$ 2 cell measured at a current density of $0.3 \mathrm{~mA} \mathrm{~cm}^{-2}$ for $18 \mathrm{~h}$ of discharge and then for $13.4 \mathrm{~h}$ of charge is shown in Figure 2d (discharge corresponds to $\mathrm{Li}$ stripping from the $\mathrm{Li}$ negative electrode, charge corresponds to $\mathrm{Li}$ plating onto the $\mathrm{Li}$ negative electrode. The "negative" $\mathrm{Li}$ electrode and "positive" Li electrode are defined during the $1^{\text {st }}$ discharge and are also used during the $1^{\text {st }}$ charge). As indicated by two black arrows, there is a steep voltage dip at the beginning of $\mathrm{Li}$ metal deposition during both discharge and charge. The observed overpotential here is typical of a nucleation mechanism, which signifies the initiation of the growth of Li nuclei. ${ }^{54-55}$ During the charge process, the sudden voltage drop marked by the red arrow in Figure 2d indicates that ISC has occurred. The cross section of the short-circuited $\mathrm{Li} / \mathrm{Li}-2$ cell displays a significantly different morphology compared to that of the $\mathrm{Li} / \mathrm{Li}-1$ cell. A panoramic view of this situation is shown in Figure 3 (Figure $3 \mathrm{~b}$ is a reconstructed raw data tomogram allowing for a comparison with Figures 3c-h showing data after filtering and segmentation). Enlarged details are shown in Figure 4 showing both reconstructed raw data as well as segmented data. The complete threedimensional visualization of the internal structure of the $\mathrm{Li} / \mathrm{Li}-1$ and $\mathrm{Li} / \mathrm{Li}-2$ cells is shown in a supporting movie. 

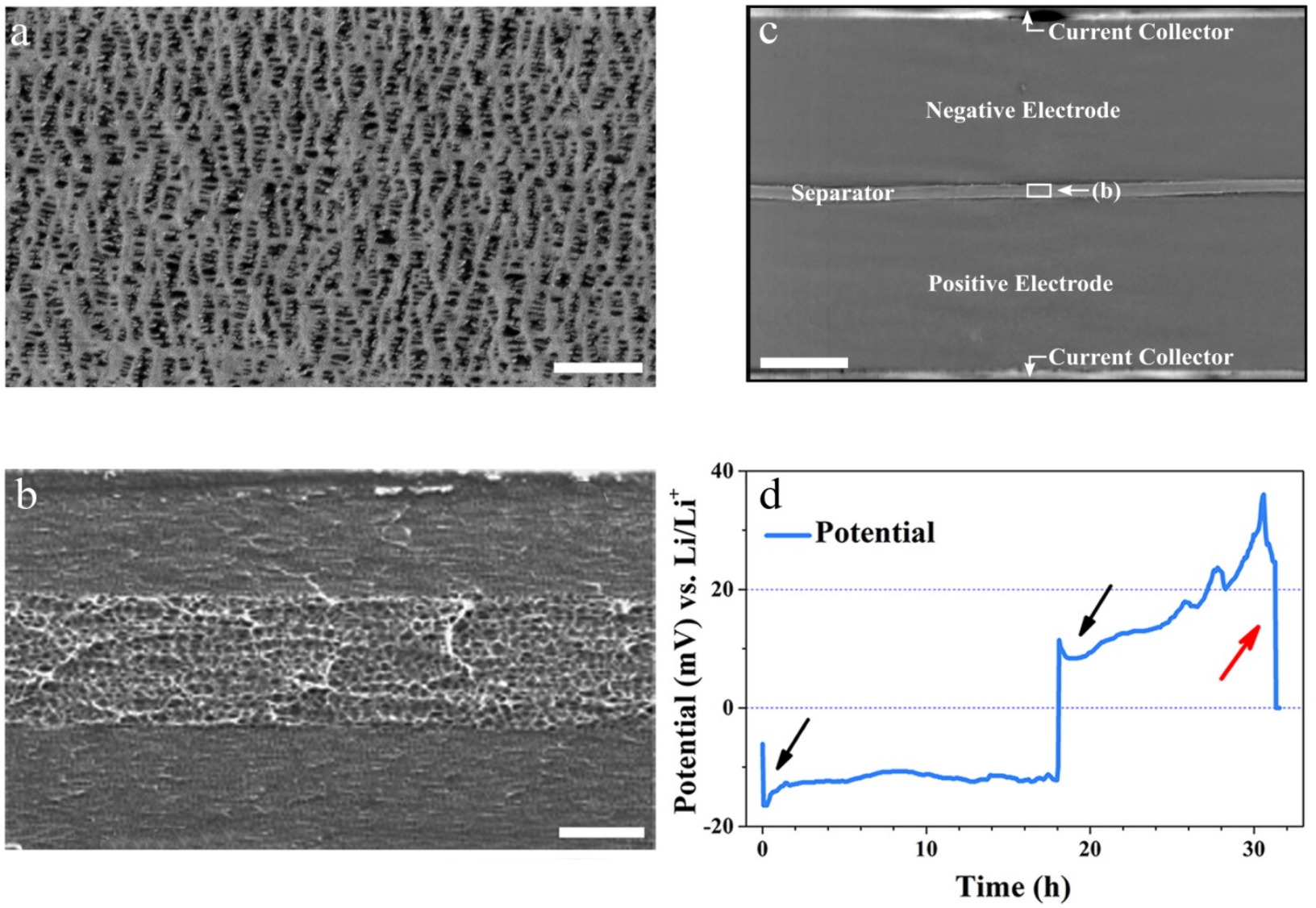

Figure 2. a) Plane view and b) Cross-sectional view of the investigated trilayer Celgard ${ }^{\circledR} 2325$ separator as obtained by scanning electron microscopy (SEM). c) Reconstructed in-line X-ray phase contrast tomography slice of the pristine Li/Li-1 cell. d) Electrochemical characterization of the investigated $\mathrm{Li} / \mathrm{Li}-2$ cell (the black arrows mark an abrupt voltage dip; the red arrow a sudden internal short circuit). Scale bars in a), b), and c) are $1 \mu \mathrm{m}, 5 \mu \mathrm{m}$, and $125 \mu \mathrm{m}$ long, respectively. Figure $2 \mathrm{~b}$ has been adopted from Ref. ${ }^{44}$, with permission by the American Chemical Society.

Preliminary inspection of morphological structures inside $\mathbf{L i} / \mathbf{L i}-2$ cell Based on our previous investigation of the morphological evolution of electrochemically plated/stripped $\mathrm{LmSs}$ in $\mathrm{Li} / \mathrm{Li}$ symmetrical cells, ${ }^{49}$ the mechanims of ISC formation induced by growing LmSs in Li/Li-2 cell is elaborately studied. Figures 3 and 4 show various horizontal and cross-sectional slices of the short-circuited $\mathrm{Li} / \mathrm{Li}-2$ cell. The initially flat electrode/separator interfaces have turned into distinctively rugged interfaces with a large cavity within the Li negative electrode and numerous electrochemically deposited LmSs on the surface of the Li positive electrode as shown in Figure 3b-e and Figure 4a,f (middle area of dark and light yellow LmS and deformed separator of gray). During the $1^{\text {st }}$ discharge, the total electron transfer (calculated from the external circuit) is $0.986 \mathrm{C}$ assuming that the total charge transfer of $\mathrm{Li}^{+}$inside the $\mathrm{Li} / \mathrm{Li}-2$ sample during the $1^{\text {st }}$ discharge occurs within the FoV (the same assumption is made for the $1^{\text {st }}$ charge). This results in $\mathrm{M}_{\text {positive }}=10^{-5} \mathrm{~mol}$ of $\mathrm{Li}$ that is stripped from the negative (generating a large cavity) and 
subsequently plated onto the surface of the Li positive electrode (developing numerous LmSs). Simultaneously, the separator is stretched and pushed into the cavity formed within the negative by the growing LmSs. Furthermore, as can be clearly observed from Figure 3c,d (pink arrows) and Figure 4e (light blue lines), cleavage of the separator into its three native layers takes place, which contributes to a decreased chord length of the separator, see Figure $5 \mathrm{~b}$ (orange line). The notable deformation and unexpected cleavage of the separator implies that enormous mechanical stresses are generated by the growing LmSs. According to the manufacturer, ${ }^{44-45}$ Celgard $^{\circledR}$ separator has a high mechanical strength in terms of tensile strength along both the machine direction (MD, $1900 \mathrm{~kg} / \mathrm{cm}^{2}$ ) and the transverse direction (TD, $135 \mathrm{~kg} / \mathrm{cm}^{2}$ ) and puncture strength $\left(300 \mathrm{~g} / \mathrm{cm}^{2}\right) .{ }^{45}$ This observation suggests that the current separator cannot withstand the high mechanical stress caused by the growing LmSs and thus has to be further improved. During the $1^{\text {st }}$ charge, the total charge transfer after the short circuit is $0.788 \mathrm{C}$, i.e. about $\mathrm{M}_{\text {negative }}=0.82 \times 10^{-}$ ${ }^{5} \mathrm{~mol}$ of $\mathrm{Li}$ is stripped from the positive and then plated onto the surface of the $\mathrm{Li}$ negative electrode.

Two observations regarding the previously formed LmSs (on the surface of the Li positive electrode, beneath the separator) and newly formed LmSs (on the surface of the Li negative electrode, above the separator) are noted: 1) most of the previously formed LmS undergoes no electrochemical dissolution (evidenced by the remaining LmSs, beneath the separator in the middle of the FoV, dark yellow and light yellow shown in Figure 3b-e and Figure 4a,f). It is the original $\mathrm{Li}$ bulk positive electrode to compensate for the depletion of $\mathrm{Li}$ ions in the electrolyte used to conduct charge transfer (as evidenced by the newly formed cavities within the Li positive electrode, marked by the white diamonds in Figure 3c-e and enlarged Figure 4d); 2) It is the peripheral region of the Li negative onto which newly $\mathrm{LmS}$ is preferentially electrochemically deposited (above the separator, shown by the white triangles in Figure 3c-e and enlarged Figure $4 d$ ), in correspondence to the regions of nascently formed cavities within the Li positive (as marked by white diamonds in Figure 3c-e and Figure 4d). The non-uniform Li stripping/plating during the $1^{\text {st }}$ cycle is clearly shown in Figure 3h, where LmSs in the middle surrounded by the separator are generated during the $1^{\text {st }}$ discharge by deposition onto the surface of the Li positive electrode. In the regions outside the separator, the LmSs are generated during the $1^{\text {st }}$ charge by deposition onto the surface of the $\mathrm{Li}$ negative electrode. By further calculating the volume fraction of LmSs (deposited on the positive during the $1^{\text {st }}$ discharge and deposited on the negative during the $1^{\text {st }}$ charge) as a function of radius $\mathrm{r}$ with respect to the central point located along $\mathrm{z}$ direction as shown in Figure 5a, one obtains volume fractions (blue straight line and dashed line) as shown in Figure 5b. Obviously, the positive LmSs are concentrated in the middle while the negative LmSs are distributed in the peripheral region. From Figure $5 b$ (orange line), one can also observe the calculated chord length of the separator (orange line): the separator located in the middle (small r) has delaminated into layers with small average thickness as deduced from the low average chord length. The reason is that the separator in the middle undergoes cleavage (see above) and partial melting (see below for more detailed explanation), while the separator in the 
peripheral region (large $\mathrm{r}$ ) is nearly intact. The observed fluctuations between $\sim 25 \mu \mathrm{m}$ to $\sim 30 \mu \mathrm{m}$ result from its morphological distortion.
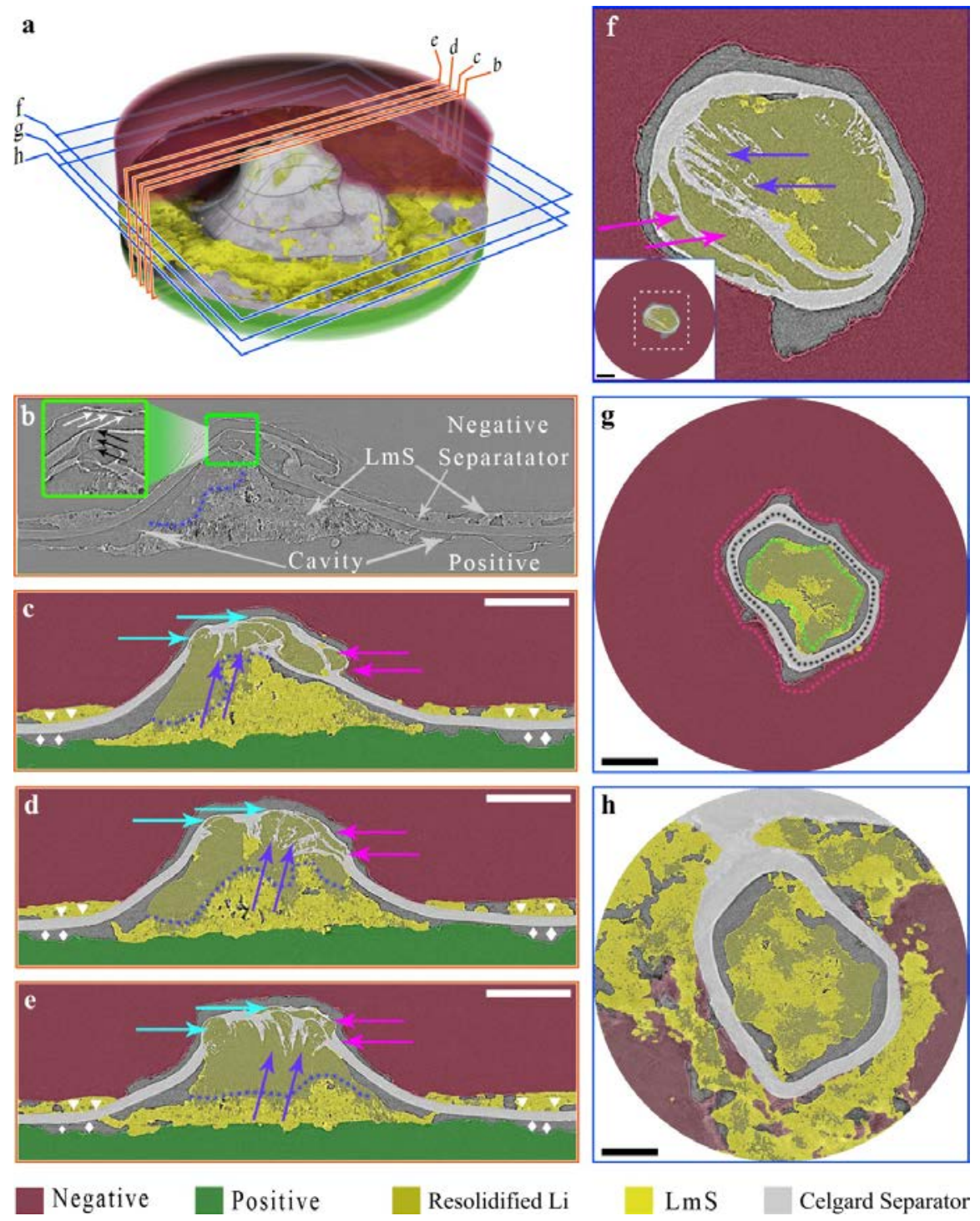

Figure 3. a) 3D visualization of the short circuited $\mathrm{Li} / \mathrm{Li}-2$ cell. Letters b-e denote selected crosssectional planes; letters f-h selected horizontal planes. The planes in Figure b)-h) are all defined in a). b) Reconstructed raw data to which neither phase filter nor segmentation was applied, it serves as a comparison for the segmented figures c)-h). In the enlarged green rectangle, black arrows point at a fiber that may be the remnant of a Li dendrite or molten separator material, white arrows point at an irregular boundary resulting probably from a fused lithium dendrite. In c)-f), light blue arrows point at the partially molten separator; purple arrows at dangling separator fibers, pink arrows at the cleavage of the separator. The purple dotted line separates the resolidified $\mathrm{Li}$ and the porous LmSs. The interesting region in figure $\mathrm{f}$ ) is enlarged as indicated by a white dotted rectangle in the inset. In g), the pink, black and green dotted lines denote the contour of the negative $\mathrm{Li}$, the separator or the LmSs, respectively. In h), the electrochemically deposited LmSs clearly appears heterogeneous. All scale bars are $250 \mu \mathrm{m}$ long. 
Comparison of the amount of LmS determined by morphological and electrochemical characterizations It has been reported that the electrochemically formed LmSs are still chemically active and that they can easily react with the electrolyte to form a solid electrolyte interface (SEI) coverage. ${ }^{56}$ As a result, the SEI formed on the surface of LmSs during the $1^{\text {st }}$ discharge electrically insulates most of the LmSs, thereby deactivating them electrochemically during the $1^{\text {st }}$ charge. ${ }^{57}$ Further confirmation of the electrochemical inertness of newly formed LmSs during ensuing electrochemical reaction is obtained by comparing the volume ratio of LmSs plated onto the positive and LmSs plated onto the negative (both calculated from X-ray tomography data) with the analogous ratio calculated from the external electron transfer during the $1^{\text {st }}$ discharge and charge. The calculation of the volume ratio of the amount of LmSs via the reconstructed tomography dataset was done by counting the number of voxels belonging to the LmSs deposited onto the positive $\left(\mathrm{V}_{\text {positive }}\right)$ and onto the negative ( $\mathrm{V}_{\text {negative). The reconstructed }}$ volume ratio $\mathrm{V}_{\text {positive }}: \mathrm{V}_{\text {negative }}=10: 5.5$ is obtained. The ratio calculated from the electrochemical characterization with $M_{\text {positive }}: M_{\text {negative }}$ is 10:8. The tendency of the deviation between these two ratios was expected and the reason is related to the limited FoV (see above). Nevertheless, the comparison between these two ratios confirms that most of the LmSs electrochemically formed during the $1^{\text {st }}$ discharge become electrochemically inactive during the $1^{\text {st }}$ charge while forming the well-known "dead LmSs". 56 This is the first time that the amount of electrochemically deposited LmSs calculated from morphological information is directly correlated with the amount of external electron transfer measured electrochemically. Concerning the locations of preferential Li dissolution and LmS deposition during cycling it has been suggested that such locations are electrochemically more active ${ }^{15}$ or possess a high local ionic conductivity. ${ }^{27}$ It has been also suggested that a localized fracture in the $\mathrm{SEI}^{58}$ and the nucleated $\mathrm{Li}$ grain size during $\mathrm{Li}$ deposition $^{59}$ may as well influence the growth of $\mathrm{LmS}$. Characterization of $\mathrm{Li} / \mathrm{Li}$ cells employing differently shaped ${ }^{60-61} \mathrm{Li}$ electrodes is planned for the future. 

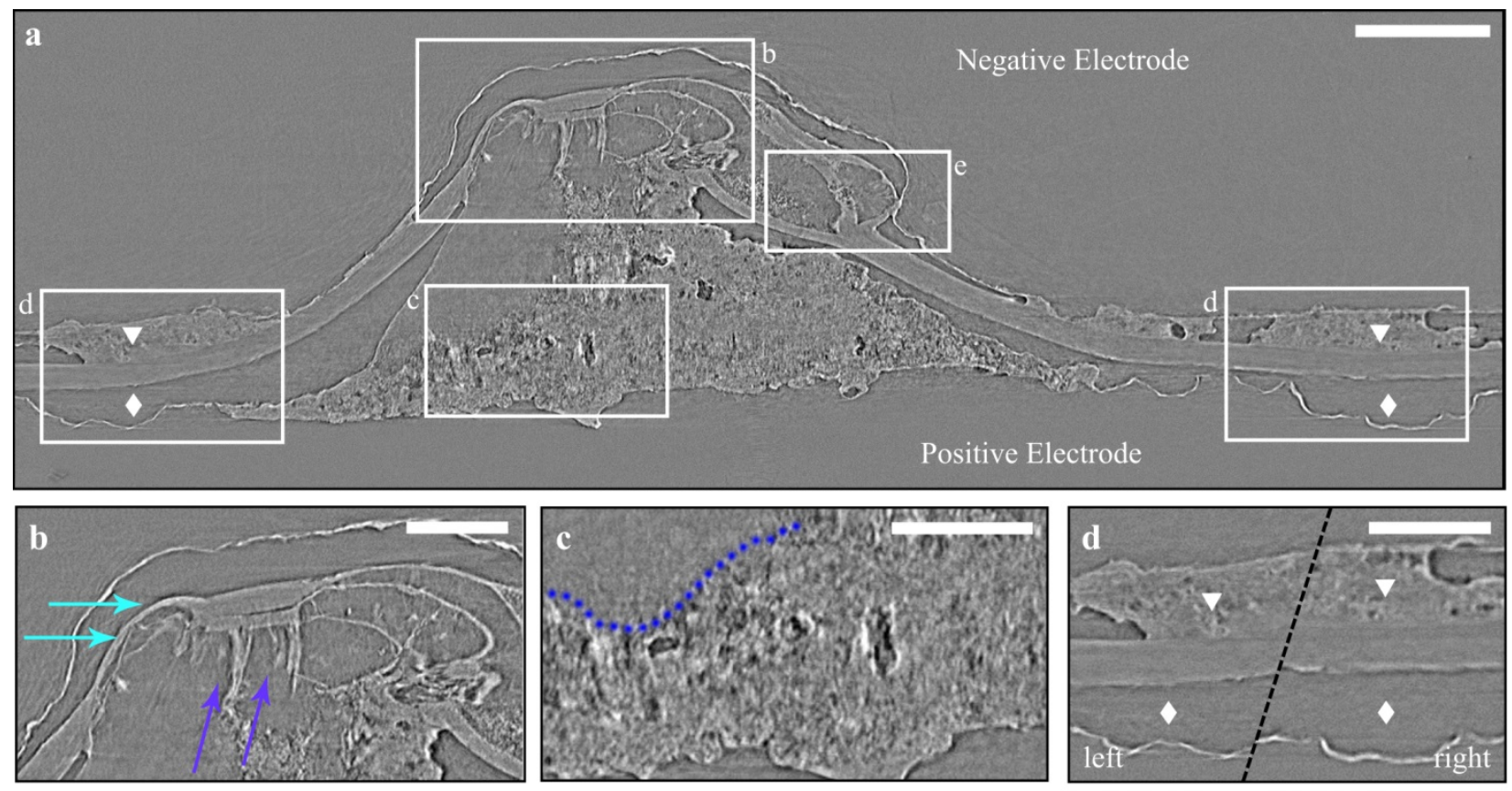

f
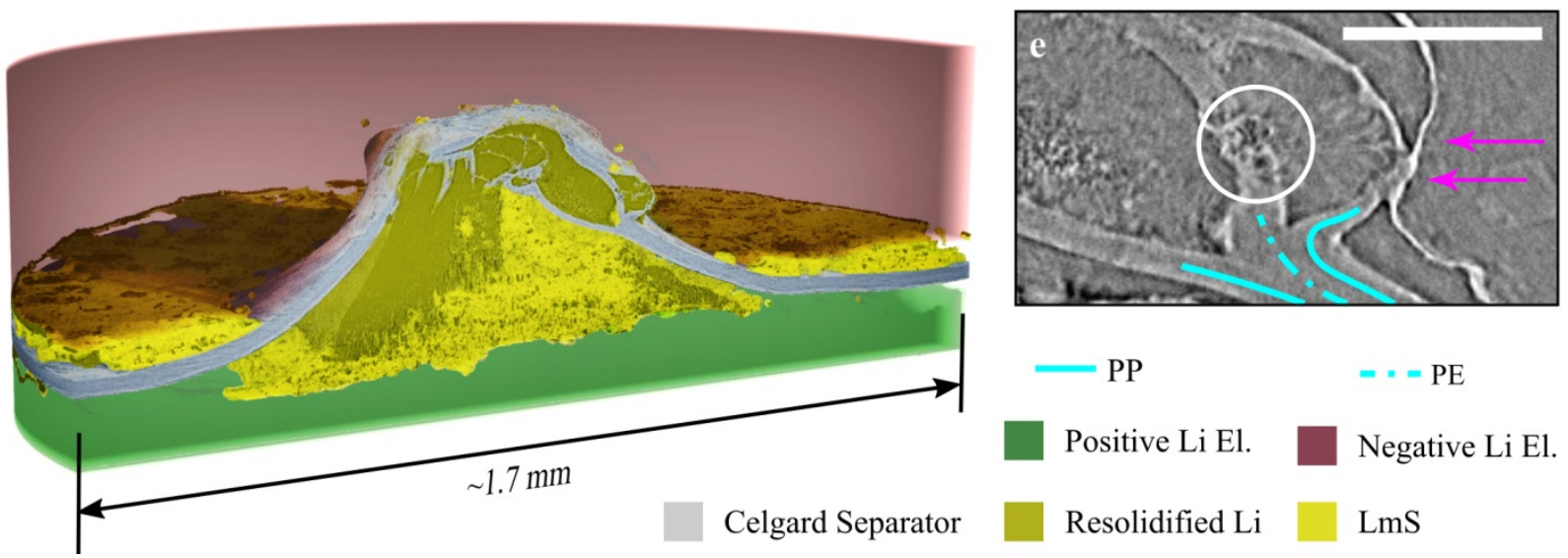

$=-" \mathrm{PE}$

Positive Li El.

Negative Li El.

Resolidified Li $\quad$ LmS

Figure 4. a) Exemplary tomogram of the short circuited Li/Li-2 cell. b)-e) Zoom-in into regions defined in a). b) The original Li negative has been electrochemically dissolved and partially filled by the separator and LmSs. The partially molten separator forming dangling fibers can also be seen (light blue and purple arrows). c) Exemplary slice shows electrochemically plated LmSs formed during the first discharge. Deposited porous LmS and compact solid LmS can be observed (separated by a purple dotted line). d) Newly formed cavities (diamonds) and LmSs (triangles) during the first charge. e) Cleavage and partial melting of the separator. a)-e) Reconstructed raw data without phase filtering and segmentation. f) Three-dimensional visualization of the segmented data set. The scale bar in a) is $150 \mu \mathrm{m}$ and scale bars in b)-e) are $75 \mu \mathrm{m}$ long. 
Close-up inspection of morphological structures inside Li/Li-2 cell Apart from these findings, a close-up inspection of Figure 3 and 4 further demonstrates: 3) there are two different phases of electrodeposited LmSs, one being porous and the other solid and compact (both are shown in Figure 3b-e and 4c,f in light yellow and dark yellow, respectively, separated by a purple dotted line). 4) A part of the originally intact separator has completely disappeared (light blue arrows in Figure 3c-e and enlarged in Figure 4b). At other positions, the separator has molten into filamentary fibers that dangle into the solid and the compact LmS phase (purple arrows in Figure 3c-e and enlarged in Figure 4b). This also contributes to the decreased average chord length of the separator in the middle region, see Figure $5 b$ (orange line). The currently observed porous LmS phase agrees well with previous characterizations ${ }^{42}$ and the highlighted pore structures are attributed to the high-surface area lithium (HSAL) compound that is composed of decomposed lithium salt precipitates according to Eastwood et al. ${ }^{42}$ We suspect that this HSAL compound consists of porous LmSs covered by SEI formed during electrochemical plating of $\mathrm{Li}$ and numerous voids within. ${ }^{56}$ If one compares porous LmS (light yellow) with solid and compact LmS (dark yellow) one can conclude that the SEI and the voids in the porous LmS have completely dissolved or depleted. Richard and Dahn have indeed identified an exothermic peak due to SEI decomposition at $\sim 100{ }^{\circ} \mathrm{C}$ in accelerating rate calorimetry (ARC) studies of the thermal stability of LIBs. ${ }^{62}$ Furthermore, Maleki et al. have also confirmed exothermic SEI decomposition peak at $\sim 100{ }^{\circ} \mathrm{C}$ by differential scanning calorimetry (DSC). ${ }^{63}$ The currently observed disappearance of both SEI and voids in porous LmS may be attributed to hightemperature melting. Regarding the disappearance and the meltdown of the separator, Cai et al. ${ }^{64}$ and Malekei et $a l .{ }^{65}$ have independently observed separator melting around the ISC location inside LIBs by post-mortem light microscopy. They concluded that the thermal energy induced by an ISC is sufficient to locally increase the temperature of a cell by $200 \mathrm{~K}$, which can easily melt PE (m.p. $135{ }^{\circ} \mathrm{C}$ ), PP (m.p. $165^{\circ} \mathrm{C}$ ) and $\mathrm{Li}$ (m.p. $180{ }^{\circ} \mathrm{C}$ ) ${ }^{66}$ Considering the decomposition of SEI and the melting of the separator together with the electrochemical characterization (a sudden voltage drop in Figure 2d), it can be concluded that an ISC occurs during charge. This is the first experimental demonstration of the melting of the separator and the porous LmS phase in a nondestructive and three-dimensional way. 

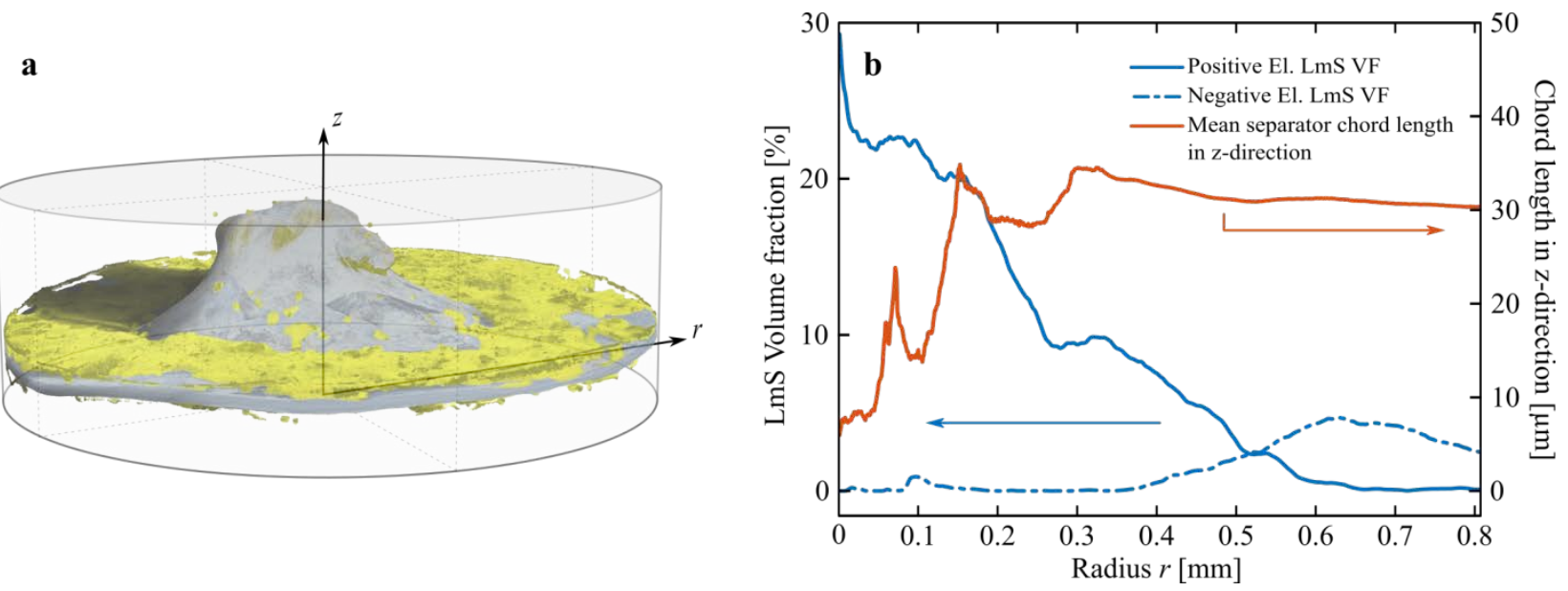

Figure 5. a) 3D visualization of the calculated LmS volume fraction (VF) deposited on both the positive (here invisible, beneath the gray separator) and the negative (light yellow, above the separator). The $\mathrm{r}$ and $\mathrm{z}$ directions are also shown. b) Calculated LmS volume fraction deposited on both the Li positive (blue solid line) and Li negative (blue dashed line) as a function of r; the calculated chord length of the separator in the $\mathrm{z}$ direction as a function of $\mathrm{r}$ is shown by the orange line (the chord length of the separator in the central region is small due to partial separator cleavage and melting, but is large in the peripheral region because the separator is intact there).

Discussion based on the inspection of short-circuited $\mathbf{L i} / \mathbf{L i}-\mathbf{2}$ cell By checking intensively the region of separator breakdown, one finds that one fiber remnant is located inside the delaminated separator, pointing towards the positive LmS with the surrounding separator molten away. This phenomenon is marked by black arrows in the green rectangle in Figure 3b. The diameter of this fiber is about $2 \mu \mathrm{m}$. In the green rectangle, the irregular boundaries, marked by white arrows, are also shown. We suspect that the irregular boundaries result from the fusing of some Li dendrites and that the remnant fiber is closely related to the ISC (due to a similar X-ray absorption coefficient this fiber cannot be assigned to the separator or to Li with certainty). During charging most of the LmSs are electrochemically deposited preferentially in the outer region, but one dendrite is electrochemically generated in this specific area (lithium is probably supplied by the electrolyte). During its growth it can easily penetrate the pores of this part of the separator since this part has already been significantly stretched and its mechanical robustness has already been weakened by the LmS growing during discharge. ${ }^{44}$ Once this dendrite eventually perforates the separator and bridges the Li negative and positive electrode the entire cell current (0.015 mA) concentrates only on a spot with $\sim 2 \mu$ m diameter (the penetrating dendrite), which results in a high current density of about $470 \mathrm{~A} \mathrm{~cm}^{-2}$ and pronounced localized Joule heating around the ISC location. According to previous calculations, ${ }^{67}$ within less than $\sim 0.1 \mathrm{~s}$ the induced Joule heat will lead to the decomposition of the SEI and the melting of both the separator and porous LmS phase. Most of the energy is dissipated by the endothermic melting of the porous LmS and the separator and within $\sim 0.4 \mathrm{~s}$, the temperature drops sharply. ${ }^{67}$ The above-observed results agree well with previous simulations. ${ }^{15,68-69}$ Additionally, the direct internal view of the electrochemically short 
circuited $\mathrm{Li} / \mathrm{Li}-2$ cell suggests that the shutdown mechanism proposed by the sandwich structure can hardly provide any protection from a real ISC, i.e. the considerable force accompanied by the growing LmSs and the ISC-induced high Joule heating easily destroy the trilayer separator that is made by laminating PP and PE layers together by adhesion or welding. ${ }^{45,70}$ The decomposition of the SEI and the melting of the porous LmS to a more compact resolidified LmS will release most of the mechanical stress that acted on the separator (the affine transformation between the contours of the LmSs, separator and Li negative, as marked by a green dotted line, a black dotted line and a pink dotted line in Figure 3g, provides evidence for the movement of the separator during stress relief). In the $\mathrm{Li} / \mathrm{Li}-2$ cell investigated, most of the Joule heat is dissipated by the endothermic melting of the separator ${ }^{71}$ after the penetrating $\mathrm{Li}$ dendrite has been fused. ${ }^{72}$ However, in real commercial LIBs containing normal cathode materials such as $\mathrm{LiCoO}_{2}$, $\mathrm{LiMn}_{2} \mathrm{O}_{4}$ and $\mathrm{LiFePO}_{4}$ etc. and anode materials such as lithiated carbon, an ISC-induced Joule heating will initiate the exothermic decomposition of some of the active materials including the release of oxygen and flammable gas. ${ }^{70}$ Such reactions can further increase the inner temperature to above $200{ }^{\circ} \mathrm{C}$ and lead to the exothermic decomposition or ignition of the flammable electrolyte. ${ }^{20,73}$ Ultimately, without an effective heat dissipation or propagation within LIBs, the lithium-dendrite induced ISC can eventually result in serious incidents. Table 1 summary some particular parameters of commercial LIB components. ${ }^{44,74-75}$

Table 1. Specific property parameters of selected commercial LIB components.

\begin{tabular}{|l|l|l|l|l|}
\hline & $\begin{array}{l}\text { Tensile strength } \\
\left(\mathrm{kg} \mathrm{cm}^{-2}\right)\end{array}$ & $\begin{array}{l}\text { Puncture strength } \\
\left(\mathrm{g} \mathrm{cm}^{-2}\right)\end{array}$ & $\begin{array}{l}\text { Melting } \\
\text { temperature }\left({ }^{\circ} \mathrm{C}\right)\end{array}$ & $\begin{array}{l}\text { Decomposition } \\
\text { temperature }\left({ }^{\circ} \mathrm{C}\right)\end{array}$ \\
\hline $\begin{array}{l}\text { Celgard }{ }^{\circledR} 2325 \\
\text { PP/PE/PP } \\
\text { separator }\end{array}$ & $\begin{array}{l}1900 / 135 \\
(\mathrm{MD} / \mathrm{TD})\end{array}$ & 300 & $135 / 165(\mathrm{PE} / \mathrm{PP})$ & - \\
\hline $\begin{array}{l}\text { SEI (solid } \\
\text { electrolyte } \\
\text { interface) }\end{array}$ & - & - & - & $90-120^{\mathrm{b}}$ \\
\hline Electrolyte & - & - & - & $130-230^{\mathrm{a}}$ \\
\hline Lithium & - & - & 180 & - \\
\hline $\begin{array}{l}\text { Carbon (fully } \\
\text { charged) }\end{array}$ & - & - & - & $100-130$ \\
\hline $\begin{array}{l}\text { LiCoO } \\
\text { charged) }\end{array}$ & - & - & - & $178-250$ \\
\hline
\end{tabular}

a, electrolyte decomposition temperature varies among different electrolyte, this temperature range is based on PC/EC/DMC (1/1/3)+ $\mathrm{LiPF}_{6}(1 \mathrm{M})^{74}\left[\mathrm{PC}: \mathrm{C}_{4} \mathrm{H}_{6} \mathrm{O}_{3} ; \mathrm{EC}: \mathrm{C}_{3} \mathrm{H}_{4} \mathrm{O}_{3} ; \mathrm{DMC}: \mathrm{C}_{3} \mathrm{H}_{6} \mathrm{O}_{3}\right]$ $\mathrm{b}$, SEI decomposition temperature depends on the electrolyte used, more information can be found elsewhere. ${ }^{20}$ 
In summary, for the first time, the underlying internal cell deformation and degradation caused by an ISC has been experimentally visualized by using synchrotron X-ray phase contrast tomography. By comparing reconstructed tomographies of an uncycled $\mathrm{Li} / \mathrm{Li}$ cell and a shortcircuited $\mathrm{Li} / \mathrm{Li}$ cell we experimentally demonstrate for the first time:

1. most of the electrochemically deposited lithium microstructures (LmSs) are electrochemically inert during the following Li stripping,

2. electrochemical stripping and plating during discharge and charge are non-uniform in space,

3. delamination into three native layers and the partial melting of the commercial trilayer Celgard $^{\circledR} 2325$ separator can develop during real ISC event,

4. decomposition of the solid electrolyte interface (SEI) covering the LmSs and partial melting and re-solidification of porous LmSs can occur due to the localized excessive Joule heating resulted from the ISC event.

These unexpected insights into the internal cell degradation and deformation mechanisms caused by ISC shed new lights on enhancing the properties of separators and could open up new design principles and opportunities to fundamentally improve the reliability and safety of current- and/or next-generation LIBs. From the battery engineer's point of view, the present study suggests three potential ways to further enhance the safety and reliability of current and next-generation LIBs: i) LmSs that are electrochemically plated on the surface of $\mathrm{Li}$ electrodes should be perfectly manipulated or even completely avoided. There have been reports of a directly controlled plating of LmSs on the surface of Li electrodes ${ }^{54,60}$ and the direct engineering of $\mathrm{Li}$ electrodes. ${ }^{76}$ The room-temperature liquid alloy may also be a potential strategy to provide dendrite-free anode in contact with an organic liquid electrolyte when serving as anode materials. ${ }^{77}$ ii) New kinds of separators with considerably improved mechanical and puncture strength as well as higher thermal stability (m.p. above $165^{\circ} \mathrm{C}$ ) are highly desired. Promising candidates are ceramic separators which combine the characteristics of flexible polymers and excellent thermal stability. ${ }^{78-79}$ iii) Novel electrolytes with enhanced thermal stability and non-flammability are desired. Although adding fire retardant (FR) additives to lower the flammability of the liquid electrolytes can, to some extent, reduce the flammability of liquid organic electrolytes, ${ }^{20}$ the recently emerging solid state electrolytes, which function as both electrolyte and separator, may be the most promising option for current or next-generation LIBs with enhanced safety and reliability. ${ }^{10,80-82}$ From the battery tester's point of view, the present investigation may open up new opportunities for future standard battery testing procedures. Conventional mechanical evaluation techniques have been criticized because they only show how the cells behave under an abuse condition instead of truly replicating the conditions of a field failure. ${ }^{22}$ The first successful direct visualization of an ISC conducted by synchrotron X-ray imaging may help in updating existing testing standards and creating new ones for next-generation LIB technology. 


\section{EXPERIMENTAL METHODS}

Lithium and Celgard ${ }^{\circledR} 2325$ separator were purchased from MTI Corp. USA. The electrolyte is $1 \mathrm{M} \mathrm{LiPF}_{6}$ in a volume-ratio mixture (1:1) of ethylene carbonate (EC) and ethyl methyl carbonate (EMC) and was purchased from Sigma Aldrich. The housing of the proof-of-concept beamline battery was made of polyamide-imide (Torlon) provided by Drake Plastics Europe.

The lithium electrodes in both $\mathrm{Li} / \mathrm{Li}$ cells $(2.5 \mathrm{~mm}$ diameter) were punched out from a 1-mm thick lithium plate. Both cells were assembled in an argon-filled glovebox with humidity and oxygen levels below $0.1 \mathrm{ppm}$. The trilayer Celgard ${ }^{\circledR} 2325$ separator ( $3.5 \mathrm{~mm}$ in diameter and $\sim 25 \mu \mathrm{m}$ thick) was placed between the $\mathrm{Li} / \mathrm{Li}$ electrodes. All cells were assembled manually without exerting forces. Finally, both cells were filled with $0.2 \mathrm{~mL}$ standard liquid electrolyte and were sealed off before taking them out of the glovebox. In current investigation, the trilayer separator is employed because of its proposed "shut-down" function. However, investigations of other kinds of single layer separators made of PP or PE are planned in future work.

Galvanostatic charge and discharge of the $\mathrm{Li} / \mathrm{Li}-2$ battery was carried out using an IviumStat from Ivium Technologies, Netherlands. The cells were discharged for $18 \mathrm{~h}$ and charged for $13.4 \mathrm{~h}$ at a current density of $0.3 \mathrm{~mA} \cdot \mathrm{cm}^{-2}$. However, the effect of different current densities on the growth of LmSs is worth studying in the future.

Synchrotron X-ray tomography was carried out at the BAMline at BESSY II of the HelmholtzCentre Berlin, Germany. The synchrotron beam was monochromatized to $20 \mathrm{keV}$ using a double multilayer monochromator with an energy resolution of about $1.5 \%$. The detector system comprised a $60-\mu \mathrm{m}$ thick $\mathrm{CdWO}_{4}$ scintillator, a microscopic optic and a pco4000 camera equipped with a $4008 \times 2672$ pixels CCD chip that is kept out of the direct beam by using a mirror. For tomography measurements of both cells, 2200 projections with each $2.5 \mathrm{~s}$ exposure time within a $180^{\circ}$ battery rotation were recorded.

The raw tomography data was filtered, normalized and reconstructed using code programmed in IDL 8.2. Three-dimensional segmentations of the separators were made using a grid of manually marked points that were fitted with a biharmonic equation using MATLAB. For the segmentation of LmSs, the statistical region merger tool implemented in Fiji ${ }^{33}$ was used followed by manual removal of the bulk lithium background.

\section{ASSOCIATD CONTENT}

- Supporting Movie

- Supporting Movie is available free of charge on the ACS Publications website. 


\section{ACKNOWLEDGEMENTS}

We thank Dr. Heinrich Riesemeier, the beamline scientist at BESSY II, for his valuable assistance and engineer Norbert Beck for fabricating the beamline battery. We also thank Christiane Förster for preparing the SEM sample and Anna Manzoni for conducting the SEM measurement. This work is sponsored by the Helmholtz Association and the China Scholarship Council.

\section{REFERENCES}

(1) Wang, S.; Ding, Y.; Zhou, G.; Yu, G.; Manthiram, A. Durability of the $\mathrm{Li}_{1+\mathrm{x}} \mathrm{Ti}_{2-\mathrm{x}} \mathrm{Al}_{\mathrm{x}}\left(\mathrm{PO}_{4}\right)_{3}$ Solid Electrolyte in Lithium-Sulfur Batteries. ACS Energy Lett. 2016, 1, 1080-1085.

(2) Sun, X.; Hao, G.-P.; Lu, X.; Xi, L.; Liu, B.; Si, W.; Ma, C.; Liu, Q.; Zhang, Q.; Kaskel, S.; et al. High-Defect Hydrophilic Carbon Cuboids Anchored with $\mathrm{Co} / \mathrm{CoO}$ Nanoparticles as Highly Efficient and Ultra-Stable Lithium-Ion Battery Anodes. J. Mater. Chem. A 2016, 4, 10166-10173.

(3) Fu, K. K.; Cheng, J.; Li, T.; Hu, L. Flexible Batteries: From Mechanics to Devices. ACS Energy Lett. 2016, 1, 1065-1079.

(4) Sun, X.; Yan, C.; Chen, Y.; Si, W.; Deng, J.; Oswald, S.; Liu, L.; Schmidt, O. G. ThreeDimensionally "Curved" NiO Nanomembranes as Ultrahigh Rate Capability Anodes for LiIon Batteries with Long Cycle Lifetimes. Adv. Energy Mater. 2014, 4, 1300912-1300918.

(5) Zu, C.; Manthiram, A. Stabilized Lithium-Metal Surface in a Polysulfide-Rich Environment of Lithium-Sulfur Batteries. J. Phys. Chem. Lett. 2014, 5, 2522-2527.

(6) Sun, X.; Si, W.; Xi, L.; Liu, B.; Liu, X.; Yan, C.; Schmidt, O. G. In Situ-Formed, Amorphous, Oxygen-Enabled Germanium Anode with Robust Cycle Life for Reversible Lithium Storage. ChemElectroChem 2015, 2, 737-742.

(7) Zhao, Y.; Liu, X.; Li, H.; Zhai, T.; Zhou, H. Hierarchical Micro/Nano Porous Silicon Li-Ion Battery Anodes. Chem. Commun. 2012, 48, 5079-5081.

(8) Lim, B.; Jin, J.; Yoo, J.; Han, S. Y.; Kim, K.; Kang, S.; Park, N.; Lee, S. M.; Kim, H. J.; Son, S. U. $\mathrm{Fe}_{3} \mathrm{O}_{4}$ Nanosphere@Microporous Organic Networks: Enhanced Anode Performances in Lithium Ion Batteries through Carbonization. Chem. Commun. 2014, 50, 7723-7726.

(9) Sun, F.; Huang, K.; Qi, X.; Gao, T.; Liu, Y.; Zou, X.; Wei, X.; Zhong, J. A Rationally Designed Composite of Alternating Strata of Si Nanoparticles and Graphene: A HighPerformance Lithium-Ion Battery Anode. Nanoscale 2013, 5, 8586-8592.

(10) Wang, Y.; Richards, W. D.; Ong, S. P.; Miara, L. J.; Kim, J. C.; Mo, Y.; Ceder, G. Design Principles for Solid-State Lithium Superionic Conductors. Nat Mater 2015, 14, 1026-1031.

(11) Sun, B.; Huang, K.; Qi, X.; Wei, X.; Zhong, J. Rational Construction of a Functionalized $\mathrm{V}_{2} \mathrm{O}_{5}$ Nanosphere/MWCNT Layer-by-Layer Nanoarchitecture as Cathode for Enhanced Performance of Lithium-Ion Batteries. Adv. Funct. Mater. 2015, 25, 5633-5639.

(12) Zheng, G.; Wang, C.; Pei, A.; Lopez, J.; Shi, F.; Chen, Z.; Sendek, A. D.; Lee, H.-W.; Lu, Z.; Schneider, H.; et al. High-Performance Lithium Metal Negative Electrode with a Soft and Flowable Polymer Coating. ACS Energy Lett. 2016, 1247-1255.

(13) Sun, X.; Si, W.; Liu, X.; Deng, J.; Xi, L.; Liu, L.; Yan, C.; Schmidt, O. G. Multifunctional $\mathrm{Ni} / \mathrm{NiO}$ Hybrid Nanomembranes as Anode Materials for High-Rate Li-Ion Batteries. Nano Energy 2014, 9, 168-175. 
(14) Sun, X.; Wang, X.; Qiao, L.; Hu, D.; Feng, N.; Li, X.; Liu, Y.; He, D. Electrochemical Behaviors of Porous $\mathrm{SnO}_{2}-\mathrm{Sn} / \mathrm{C}$ Composites Derived from Pyrolysis of $\mathrm{SnO}_{2}$ /Poly(Vinylidene Fluoride). Electrochim. Acta 2012, 66, 204-209.

(15) Grande, L.; von Zamory, J.; Koch, S. L.; Kalhoff, J.; Paillard, E.; Passerini, S. Homogeneous Lithium Electrodeposition with Pyrrolidinium-Based Ionic Liquid Electrolytes. ACS Appl. Mater. Interfaces 2015, 7, 5950-5958.

(16) Liang, Z.; Zheng, G.; Liu, C.; Liu, N.; Li, W.; Yan, K.; Yao, H.; Hsu, P.-C.; Chu, S.; Cui, Y. Polymer Nanofiber-Guided Uniform Lithium Deposition for Battery Electrodes. Nano Lett. 2015, 15, 2910-2916.

(17) Wu, H.; Zhuo, D.; Kong, D.; Cui, Y. Improving Battery Safety by Early Detection of Internal Shorting with a Bifunctional Separator. Nat Commun 2014, 5, 5193-5199.

(18) Deng, D. Li-Ion Batteries: Basics, Progress, and Challenges. Energy Sci. Eng. 2015, 3, 385418.

(19) Ren, F.; Cox, T.; Wang, H. Thermal Runaway Risk Evaluation of Li-Ion Cells Using a Pinch-Torsion Test. J. Power Sources 2014, 249, 156-162.

(20) Wang, Q.; Ping, P.; Zhao, X.; Chu, G.; Sun, J.; Chen, C. Thermal Runaway Caused Fire and Explosion of Lithium Ion Battery. J. Power Sources 2012, 208, 210-224.

(21) Orendorff, C. J.; Roth, E. P.; Nagasubramanian, G. Experimental Triggers for Internal Short Circuits in Lithium-Ion Cells. J. Power Sources 2011, 196, 6554-6558.

(22) Lamb, J.; Orendorff, C. J. Evaluation of Mechanical Abuse Techniques in Lithium Ion Batteries. J. Power Sources 2014, 247, 189-196.

(23) Wang, H.; Simunovic, S.; Maleki, H.; Howard, J. N.; Hallmark, J. A. Internal Configuration of Prismatic Lithium-Ion Cells at the Onset of Mechanically Induced Short Circuit. J. Power Sources 2016, 306, 424-430.

(24) Steiger, J.; Kramer, D.; Mönig, R. Microscopic Observations of the Formation, Growth and Shrinkage of Lithium Moss During Electrodeposition and Dissolution. Electrochim. Acta 2014, 136, 529-536.

(25) Bhattacharyya, R.; Key, B.; Chen, H.; Best, A. S.; Hollenkamp, A. F.; Grey, C. P. In Situ NMR Observation of the Formation of Metallic Lithium Microstructures in Lithium Batteries. Nat Mater 2010, 9, 504-510.

(26) Chandrashekar, S.; Trease, N. M.; Chang, H. J.; Du, L.-S.; Grey, C. P.; Jerschow, A. ${ }^{7}$ Li MRI of Li Batteries Reveals Location of Microstructural Lithium. Nat Mater 2012, 11, 311315.

(27) Li, W.; Zheng, H.; Chu, G.; Luo, F.; Zheng, J.; Xiao, D.; Li, X.; Gu, L.; Li, H.; Wei, X.; et al. Effect of Electrochemical Dissolution and Deposition Order on Lithium Dendrite Formation: A Top View Investigation. Faraday. Discuss. 2014, 176, 109-124.

(28) Orsini, F.; Du Pasquier, A.; Beaudoin, B.; Tarascon, J. M.; Trentin, M.; Langenhuizen, N.; De Beer, E.; Notten, P. In Situ Scanning Electron Microscopy (SEM) Observation of Interfaces within Plastic Lithium Batteries. J. Power Sources 1998, 76, 19-29.

(29) Ghassemi, H.; Au, M.; Chen, N.; Heiden, P. A.; Yassar, R. S. Real-Time Observation of Lithium Fibers Growth inside a Nanoscale Lithium-Ion Battery. Appl. Phys. Lett. 2011, 99, 123113-123116.

(30) Liu, X. H.; Zhong, L.; Zhang, L. Q.; Kushima, A.; Mao, S. X.; Li, J.; Ye, Z. Z.; Sullivan, J. P.; Huang, J. Y. Lithium Fiber Growth on the Anode in a Nanowire Lithium Ion Battery During Charging. Appl. Phys. Lett. 2011, 98, 183107-183110. 
(31) Jung, Y. S.; Cavanagh, A. S.; Gedvilas, L.; Widjonarko, N. E.; Scott, I. D.; Lee, S.-H.; Kim, G.-H.; George, S. M.; Dillon, A. C. Improved Functionality of Lithium-Ion Batteries Enabled by Atomic Layer Deposition on the Porous Microstructure of Polymer Separators and Coating Electrodes. Adv. Energy Mater. 2012, 2, 1022-1027.

(32) Zhang, J.; Liu, Z.; Kong, Q.; Zhang, C.; Pang, S.; Yue, L.; Wang, X.; Yao, J.; Cui, G. Renewable and Superior Thermal-Resistant Cellulose-Based Composite Nonwoven as Lithium-Ion Battery Separator. ACS Appl. Mater. Interfaces 2013, 5, 128-134.

(33) Xu, W.; Wang, Z.; Shi, L.; Ma, Y.; Yuan, S.; Sun, L.; Zhao, Y.; Zhang, M.; Zhu, J. Layerby-Layer Deposition of Organic-Inorganic Hybrid Multilayer on Microporous Polyethylene Separator to Enhance the Electrochemical Performance of Lithium-Ion Battery. ACS Appl. Mater. Interfaces 2015, 7, 20678-20686.

(34) Zhu, X.; Jiang, X.; Ai, X.; Yang, H.; Cao, Y. A Highly Thermostable Ceramic-Grafted Microporous Polyethylene Separator for Safer Lithium-Ion Batteries. ACS Appl. Mater. Interfaces 2015, 7, 24119-24126.

(35) Kalhoff, J.; Eshetu, G. G.; Bresser, D.; Passerini, S. Safer Electrolytes for Lithium-Ion Batteries: State of the Art and Perspectives. ChemSusChem 2015, 8, 2154-2175.

(36) Huang, F.; Xu, Y.; Peng, B.; Su, Y.; Jiang, F.; Hsieh, Y.-L.; Wei, Q. Coaxial Electrospun Cellulose-Core Fluoropolymer-Shell Fibrous Membrane from Recycled Cigarette Filter as Separator for High Performance Lithium-Ion Battery. ACS Sustainable Chem. Eng. 2015, 3, 932-940.

(37) Ji, X.; Liu, D.-Y.; Prendiville, D. G.; Zhang, Y.; Liu, X.; Stucky, G. D. Spatially Heterogeneous Carbon-Fiber Papers as Surface Dendrite-Free Current Collectors for Lithium Deposition. Nano Today 2012, 7, 10-20.

(38) Woo, J.-J.; Zhang, Z.; Amine, K. Separator/Electrode Assembly Based on Thermally Stable Polymer for Safe Lithium-Ion Batteries. Adv. Energy Mater. 2014, 4, 1301208-1301212.

(39) Bale, H. A.; Haboub, A.; MacDowell, A. A.; Nasiatka, J. R.; Parkinson, D. Y.; Cox, B. N.; Marshall, D. B.; Ritchie, R. O. Real-Time Quantitative Imaging of Failure Events in Materials under Load at Temperatures above $1,600^{\circ} \mathrm{C}$. Nat Mater 2013, 12, 40-46.

(40) Ebner, M.; Marone, F.; Stampanoni, M.; Wood, V. Visualization and Quantification of Electrochemical and Mechanical Degradation in Li Ion Batteries. Science 2013, 342, 716720.

(41) Eastwood, D. S.; Yufit, V.; Gelb, J.; Gu, A.; Bradley, R. S.; Harris, S. J.; Brett, D. J. L.; Brandon, N. P.; Lee, P. D.; Withers, P. J.; et al. Lithiation-Induced Dilation Mapping in a Lithium-Ion Battery Electrode by 3d X-Ray Microscopy and Digital Volume Correlation. Adv. Energy Mater. 2014, 4, 1300506-1300513.

(42) Eastwood, D. S.; Bayley, P. M.; Chang, H. J.; Taiwo, O. O.; Vila-Comamala, J.; Brett, D. J. L.; Rau, C.; Withers, P. J.; Shearing, P. R.; Grey, C. P.; et al. Three-Dimensional Characterization of Electrodeposited Lithium Microstructures Using Synchrotron X-Ray Phase Contrast Imaging. Chem. Commun. 2015, 51, 266-268.

(43) Harry, K. J.; Hallinan, D. T.; Parkinson, D. Y.; MacDowell, A. A.; Balsara, N. P. Detection of Subsurface Structures Underneath Dendrites Formed on Cycled Lithium Metal Electrodes. Nat Mater 2014, 13, 69-73.

(44) Arora, P.; Zhang, Z. Battery Separators. Chem. Rev. 2004, 104, 4419-4462.

(45) Zhang, S. S. A Review on the Separators of Liquid Electrolyte Li-Ion Batteries. J. Power Sources 2007, 164, 351-364. 
(46) Sun, F.; Markötter, H.; Zhou, D.; Alrwashdeh, S. S. S.; Hilger, A.; Kardjilov, N.; Manke, I.; Banhart, J. In Situ Radiographic Investigation of (De)Lithiation Mechanisms in a TinElectrode Lithium-Ion Battery. ChemSusChem 2016, 9, 946-950.

(47) Manke, I.; Banhart, J.; Haibel, A.; Rack, A.; Zabler, S.; Kardjilov, N.; Hilger, A.; Melzer, A.; Riesemeier, H. In Situ Investigation of the Discharge of Alkaline $\mathrm{Zn}-\mathrm{MnO}_{2}$ Batteries with Synchrotron X-Ray and Neutron Tomographies. Appl. Phys. Lett. 2007, 90, 214102-214105.

(48) Haibel, A.; Manke, I.; Melzer, A.; Banhart, J. In Situ Microtomographic Monitoring of Discharging Processes in Alkaline Cells. J. Electrochem. Soc. 2010, 157, A387-A391.

(49) Sun, F.; Zielke, L.; Markötter, H.; Hilger, A.; Zhou, D.; Moroni, R.; Zengerle, R.; Thiele, S.; Banhart, J.; Manke, I. Morphological Evolution of Electrochemically Plated/Stripped Lithium Microstructures Investigated by Synchrotron X-Ray Phase Contrast Tomography. ACS Nano 2016, 10, 7990-7997.

(50) Sun, F.; Markötter, H.; Manke, I.; Hilger, A.; Kardjilov, N.; Banhart, J. Three-Dimensional Visualization of Gas Evolution and Channel Formation inside a Lithium-Ion Battery. ACS Appl. Mater. Interfaces 2016, 8, 7156-7164.

(51) Zielke, L.; Barchasz, C.; Waluś, S.; Alloin, F.; Leprêtre, J. C.; Spettl, A.; Schmidt, V.; Hilger, A.; Manke, I.; Banhart, J.; et al. Degradation of Li/S Battery Electrodes on 3D Current Collectors Studied Using X-Ray Phase Contrast Tomography. Sci. Rep. 2015, 5, 10921-10933.

(52) Zielke, L.; Hutzenlaub, T.; Wheeler, D. R.; Chao, C.-W.; Manke, I.; Hilger, A.; Paust, N.; Zengerle, R.; Thiele, S. Three-Phase Multiscale Modeling of a $\mathrm{LiCoO}_{2}$ Cathode: Combining the Advantages of FIB-SEM Imaging and X-Ray Tomography. Adv. Energy Mater. 2015, 5, 1401612-1401620.

(53) Cloetens, P.; Pateyron-Salomé, M.; Buffière, J. Y.; Peix, G.; Baruchel, J.; Peyrin, F.; Schlenker, M. Observation of Microstructure and Damage in Materials by Phase Sensitive Radiography and Tomography. J. Appl. Phys. 1997, 81, 5878-5886.

(54) Yan, K.; Lu, Z.; Lee, H.-W.; Xiong, F.; Hsu, P.-C.; Li, Y.; Zhao, J.; Chu, S.; Cui, Y. Selective Deposition and Stable Encapsulation of Lithium through Heterogeneous Seeded Growth. Nat. Energy. 2016, 1, 16010-16018.

(55) Porthault, H.; Decaux, C. Electrodeposition of Lithium Metal Thin Films and Its Application in All-Solid-State Microbatteries. Electrochim. Acta 2016, 194, 330-337.

(56) Lu, D.; Shao, Y.; Lozano, T.; Bennett, W. D.; Graff, G. L.; Polzin, B.; Zhang, J.; Engelhard, M. H.; Saenz, N. T.; Henderson, W. A.; et al. Failure Mechanism for Fast-Charged Lithium Metal Batteries with Liquid Electrolytes. Adv. Energy Mater. 2015, 5, 1400993-1401000.

(57) Arakawa, M.; Tobishima, S.-i.; Nemoto, Y.; Ichimura, M.; Yamaki, J.-i. This Volume Contains the Proceedings of the 6th International Meeting on Lithium Batterieslithium Electrode Cycleability and Morphology Dependence on Current Density. J. Power Sources 1993, 43, 27-35.

(58) Wood, K. N.; Kazyak, E.; Chadwick, A. F.; Chen, K.-H.; Zhang, J.-G.; Thornton, K.; Dasgupta, N. P. Dendrites and Pits: Untangling the Complex Behavior of Lithium Metal Anodes through Operando Video Microscopy. ACS Central Science 2016, 2, 790-801.

(59) Mehdi, B. L.; Stevens, A.; Qian, J.; Park, C.; Xu, W.; Henderson, W. A.; Zhang, J.-G.; Mueller, K. T.; Browning, N. D. The Impact of Li Grain Size on Coulombic Efficiency in Li Batteries. Sci. Rep. 2016, 6, 34267. 
(60) Ryou, M.-H.; Lee, Y. M.; Lee, Y.; Winter, M.; Bieker, P. Mechanical Surface Modification of Lithium Metal: Towards Improved Li Metal Anode Performance by Directed Li Plating. Adv. Funct. Mater. 2015, 25, 834-841.

(61) Hong, S.-T.; Kim, J.-S.; Lim, S.-J.; Yoon, W. Y. Surface Characterization of Emulsified Lithium Powder Electrode. Electrochim. Acta 2004, 50, 535-539.

(62) Richard, M. N.; Dahn, J. R. Accelerating Rate Calorimetry Study on the Thermal Stability of Lithium Intercalated Graphite in Electrolyte. I. Experimental. J. Electrochem. Soc. 1999, 146, 2068-2077.

(63) Maleki, H.; Deng, G.; Anani, A.; Howard, J. Thermal Stability Studies of Li-Ion Cells and Components. J. Electrochem. Soc. 1999, 146, 3224-3229.

(64) Cai, W.; Wang, H.; Maleki, H.; Howard, J.; Lara-Curzio, E. Experimental Simulation of Internal Short Circuit in Li-Ion and Li-Ion-Polymer Cells. J. Power Sources 2011, 196, 7779-7783.

(65) Maleki, H.; Howard, J. N. Internal Short Circuit in Li-Ion Cells. J. Power Sources 2009, 191, 568-574.

(66) Brand, M. J.; Schuster, S. F.; Bach, T.; Fleder, E.; Stelz, M.; Gläser, S.; Müller, J.; Sextl, G.; Jossen, A. Effects of Vibrations and Shocks on Lithium-Ion Cells. J. Power Sources 2015, 288, 62-69.

(67) Kim, C.-S.; Yoo, J.-S.; Jeong, K.-M.; Kim, K.; Yi, C.-W. Investigation on Internal Short Circuits of Lithium Polymer Batteries with a Ceramic-Coated Separator During Nail Penetration. J. Power Sources 2015, 289, 41-49.

(68) Nishikawa, K.; Mori, T.; Nishida, T.; Fukunaka, Y.; Rosso, M.; Homma, T. In Situ Observation of Dendrite Growth of Electrodeposited Li Metal. J. Electrochem. Soc. 2010, 157, A1212-A1217.

(69) Jana, A.; Ely, D. R.; García, R. E. Dendrite-Separator Interactions in Lithium-Based Batteries. J. Power Sources 2015, 275, 912-921.

(70) Dubaniewicz Jr, T. H.; DuCarme, J. P. Further Study of the Intrinsic Safety of Internally Shorted Lithium and Lithium-Ion Cells within Methane-Air. J. Loss. Prevent. Proc. 2014, 32, 165-173.

(71) Ping, P.; Wang, Q.; Huang, P.; Li, K.; Sun, J.; Kong, D.; Chen, C. Study of the Fire Behavior of High-Energy Lithium-Ion Batteries with Full-Scale Burning Test. J. Power Sources 2015, 285, 80-89.

(72) Dollé, M.; Sannier, L.; Beaudoin, B.; Trentin, M.; Tarascon, J.-M. Live Scanning Electron Microscope Observations of Dendritic Growth in Lithium/Polymer Cells. Electrochem. Solid-State Lett. 2002, 5, A286-A289.

(73) Kawamura, T.; Kimura, A.; Egashira, M.; Okada, S.; Yamaki, J.-I. Thermal Stability of Alkyl Carbonate Mixed-Solvent Electrolytes for Lithium Ion Cells. J. Power Sources 2002, 104, 260-264.

(74) Biensan, P.; Simon, B.; Pérès, J. P.; de Guibert, A.; Broussely, M.; Bodet, J. M.; Perton, F. On Safety of Lithium-Ion Cells. J. Power Sources 1999, 81-82, 906-912.

(75) Spotnitz, R.; Franklin, J. Abuse Behavior of High-Power, Lithium-Ion Cells. J. Power Sources 2003, 113, 81-100.

(76) Lee, Y.-S.; Lee, J. H.; Choi, J.-A.; Yoon, W. Y.; Kim, D.-W. Cycling Characteristics of Lithium Powder Polymer Batteries Assembled with Composite Gel Polymer Electrolytes and Lithium Powder Anode. Adv. Funct. Mater. 2013, 23, 1019-1027. 
(77) Xue, L.; Gao, H.; Zhou, W.; Xin, S.; Park, K.; Li, Y.; Goodenough, J. B. Liquid K-Na Alloy Anode Enables Dendrite-Free Potassium Batteries. Adv. Mater. 2016, 28, 9608-9612.

(78) Kim, M.; Han, G. Y.; Yoon, K. J.; Park, J. H. Preparation of a Trilayer Separator and Its Application to Lithium-Ion Batteries. J. Power Sources 2010, 195, 8302-8305.

(79) He, M.; Zhang, X.; Jiang, K.; Wang, J.; Wang, Y. Pure Inorganic Separator for Lithium Ion Batteries. ACS Appl. Mater. Interfaces 2015, 7, 738-742.

(80) Aboulaich, A.; Bouchet, R.; Delaizir, G.; Seznec, V.; Tortet, L.; Morcrette, M.; Rozier, P.; Tarascon, J.-M.; Viallet, V.; Dollé, M. A New Approach to Develop Safe All-Inorganic Monolithic Li-Ion Batteries. Adv. Energy Mater. 2011, 1, 179-183.

(81) Kamaya, N.; Homma, K.; Yamakawa, Y.; Hirayama, M.; Kanno, R.; Yonemura, M.; Kamiyama, T.; Kato, Y.; Hama, S.; Kawamoto, K.; et al. A Lithium Superionic Conductor. Nat Mater 2011, 10, 682-686.

(82) Kato, Y.; Hori, S.; Saito, T.; Suzuki, K.; Hirayama, M.; Mitsui, A.; Yonemura, M.; Iba, H.; Kanno, R. High-Power All-Solid-State Batteries Using Sulfide Superionic Conductors. Nat. Energy. 2016, 1, 16030.

(83) Abramoff, M. D.; Magalhães, P. J.; Ram, S. J. Image Processing with Imagej. Biophotonics international 2004, 11, 36-42. 